\title{
JD11
}

\section{Redshift Surveys in the 21st Century}

Chairpersons and Editors: J. Huchra \& A.P. Fairall 